\title{
Seeing and touching aesthetic objects: I. Judgments
}

\author{
MARTIN S. LINDAUER, ELENI A. STERGIOU, and DAVID L. PENN \\ State University of New York, College at Brockport, Brockport, New York
}

\begin{abstract}
An equivalence position on the senses holds that vision and touch provide similar information. Handcrafted ceramic vessels, with their potent visual and tactile properties, should therefore be similarly judged by vision and touch. Twelve affective, sensory, perceptual, and cognitive rating scales were used to compare visual, tactile, and combined visual-tactile input. In Experiment 1, subjects $(N=58)$ were presented with aesthetic ceramic objects; in Experiment 2, subjects $(N=24)$ were asked to imagine such objects; and in Experiment 3, subjects $(\mathrm{N}=29)$ were provided with broken ceramic scraps. In the latter experiment, unlike in Experiments 1 and 2, the same subjects were given all three modes of input. All studies found similarities rather than differences between the modes of presentation; and correlations between vision, touch, and vision-touch were high (i.e., equivalence between the senses was evident).
\end{abstract}

Sight and touch, according to a sensory equivalence position (J. J. Gibson, 1966; Kennedy, 1978; Owen \& Brown, 1970; von Hornbostel, 1955), should process information in parallel ways because of the unity which underlies these senses. This is why, in cross-modal or synesthetic perception (Marks, 1978), a sight is "heavy" (as in touch) and a touch is "bright" (as in sight), Phenomenological accounts of perceptual experience emphasize the often overlooked contributions of touch (J. J. Gibson, 1962, 1963, 1966; Katz, as cited in Krueger, 1970; Krueger, 1982; Revesz, 1950; Taylor, Lederman, \& R. H. Gibson, 1973). For example, touch informs us about the "innards" of an object (e.g., its temperature). Sight, in contrast, provides information about the "outwardness" or surface characteristics of things. Experimental evidence has also been marshaled to show similarities rather than differences between the two senses (Garbin \& Bernstein, 1984; E. J. Gibson, 1969; Lederman, 1982; Lederman \& Abbott, 1981; Yoshida, 1968).

Visual and tactile equivalence is nicely illustrated by sculpture. Aesthetically crafted objects demand to be touched and not simply seen. Consequently, museums post signs prohibiting people from touching objects (Rowland, 1974). Sculptured objects, unlike the more highly controlled ordinary and uninteresting objects typically used in experiments (e.g., sandpaper or painted construction wood; see Garbin \& Bernstein, 1984), provide abundant visual and tactile stimulation. In addition to providing visual information, such as color and brightness, sculp-

A briefer version of Experiment 1 was presented at the 90th Annual Meeting of the American Psychological Association, Washington, DC, 1982.

The authors wish to thank William R. Stewart for his assistance in producing the ceramic vessels for Experiment 1. Requests for reprints should be sent to M. S. Lindauer, Psychology Department, State University of New York, College at Brockport, NY 14420. D. L. Penn is now at Villanova University. ture also optimizes the unique characteristics of the tactile sense: temperature, the feel of different substances (e.g., wood, bronze, marble), slipperiness, weight, resistance, three dimensionality, texture, and the unseen reverse side.

A sensory equivalence approach, taking advantage of the highly potent sensory input provided by sculpture, predicts that the meanings attributed to aesthetic objects are highly similar. A nonequivalence model of the senses looks for differences between visual and tactile judgments, perhaps because they differ in discriminability (Krauthamer, 1968). Furthermore, vision is expected to be superior (e.g., Rock \& Victor, 1964).

In Experiment 1, ceramic vessels constructed under the supervision of a ceramist were seen, touched, or seen and touched by different groups of subjects. The vessels were rated on their sensory-perceptual-cognitive connotations. In two other experiments, modes of presentation and types of stimuli were compared. In Experiment 2, subjects imagined and then rated either the visual or tactile properties of ceramic vessels. In Experiment 3, broken and unfinished clay shards from a ceramist's studio were rated; unlike Experiments 1 and 2, all subjects received all three sensory modes.

\section{EXPERIMENT 1}

\section{Method}

A random sample of 58 undergraduate volunteers (for credit) from a general psychology class participated in the study. Thirty-three men and 25 women were randomly assigned to one of three visual and/or tactile conditions. (Nine additional subjects had participated earlier in a pilot study.)

Subjects individually served in a visual, tactile, or combined visualtactile condition. In each condition, four vessels were presented, one at a time, for $20 \mathrm{sec}$ each in a systematically counterbalanced order. In the tactile condition, subjects were told to touch each vase with both hands and to move their hands freely around the object, but not to lift or otherwise move it. A curtain in front of the vessel prevented it from 
being seen. (Each vessel was removed from the rear of the presentation area without exposing it to view.) In the visual-tactile condition, the tactile procedure was combined with a full view of the vase (there was no curtain) for $20 \mathrm{sec}$. In the visual condition, looking without touching was permitted for $20 \mathrm{sec}$. There were 24 subjects each in the visual and tactile conditions, and 10 in the combined visual-tactile condition.

Each vessel was placed in an otherwise empty light-colored box, behind a curtain, and within reaching distance of the seated subject. The experimenter stood behind and to the side of the presentation area, controlling the time, placement, and sequence of exposure. (Vessels not in use were kept out of sight.) Immediately following exposure to each vessel, the subject completed 12 7-point semantic differential scales. Three of the scales were evaluative: beautiful-ugly, like-dislike, and ordinary-unusual: 1 was cognitive: simple-complex; and the remaining 8 scales were generally sensory in their connotations. Five of the 8 were relatively equivalent in their visual and tactile inferences: delicate-rugged, small-large, thin-thick, undetailed-detailed, and straight-crooked. The remaining 3 scales were more tactile (and kinesthetic) than visual in their meanings: light-heavy, smooth-rough, and cold-hot. (A low numerical rating, in the 1-3 range, refers to the first-named of the above adjectives.) There were three orders of scales, and their poles were alternated. Each vessel was presented immediately after the scales were completed for the previous vessel (which took about 1-3 min).

The four vessels (see Figure 1) were handmade by the second author. They were constructed from light green (celadon) stoneware clay by the coil-building method, and were finished with a high-fire $\left(2400^{\circ} \mathrm{F}\right)$ glazing technique that resulted in variations of an earthy color. The vessels were approximately $31 \mathrm{~cm}$ high and relatively similar in width (about 13-15 cm at their widest); their shapes were oval, cylindrical, or a combination of both. Three of the vessels had small openings at their mouths, and one had a relatively large opening. Their texture, in general, varied from very rough and bumpy to smooth.

\section{Results}

Of the three affective scales used, only the like-dislike dimension differed for seeing and touching; however, this difference involved only the combined visual-tactile condition $[F(2,58)=6.21, p<.01$; Scheffé comparison tests were used here and throughout]. Stimuli presented in the combined mode were liked less than those either visually or tactilely presented (mean $=4.96,4.22$, and 4.09 , respectively). (Since this unexpected combined effect occurred only in Experiment 1 [cf. Richardson, Ainsley, Copsey, \& Watkins, 1980], its reliability is questionable.) The other affective scales, beautiful-ugly and ordinary-unusual, were not differentiated on the three modes of presentation $[F(2,58) \leq 2.07, p>.05]$.

Mode of input did affect the simple-complex dimension, but this depended on the stimuli used $[F(6,174)=$ $2.39, p<.05]$ : Stimulus 2 was rated more complex when judged visually than when judged in the tactile or combined presentations $($ mean $=4.72,3.85$, and 4.15 , respectively); the opposite was true of Stimulus 4 , which

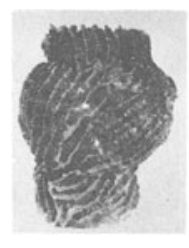

1

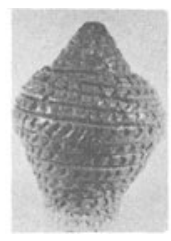

2

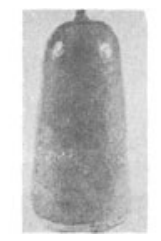

3

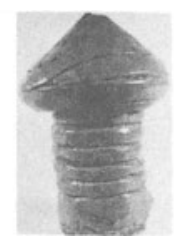

4
Figure 1. Stimuli used in Experiment 1. was judged more complex on the tactile and combined conditions than on the visual mode (mean $=4.27,4.15$, and 3.00 , respectively).

Three of the remaining eight scales showed various effects of mode. On the delicate-rugged scale, ratings based on vision and touch did not differ, but ratings based on the two senses combined had more rugged judgments [mean $=4.75,5.00$, and 5.75, respectively; $F(2,58)=$ $4.21, p<.01]$. On the light-heavy and straight-crooked scales, mode of input interacted with the stimulus used $[F(6,174)=2.34$ and 2.69 , respectively, $p<.05]$; the visual mode, in all but one instance, differed from the tactile and combined conditions. In no instance did the sex of subjects interact with mode of input $[F(2,58) \leq$ $2.22, p>.05]$.

In summary, mode of input, by itself, did not play a role in 10 of the 12 sets of judgments. Input mode was a factor on three scales, but this depended on the stimuli used.

The high degree of similarity between the visual, tactile, and visual-tactile judgments was also reflected in a correlational analysis of the data. The correlation between the mean visual and tactile responses to the set of 12 scales was .97. [Means were based on the combined responses of both sexes to all four vessels. For this and the following correlations, $r(10) \geq .58, p<.05$, two-tailed tests.] Similarly high relationships were found between the visual-tactile combined condition and both the visual and tactile conditions alone ( $r=.87$ and .85 , respectively). The correlations between the three sensory conditions for each sex considered separately was also high $\left(r_{\text {men }} \geq .79\right.$ and $r_{\text {women }} \geq .68$ ). A similar profile emerges when the three sensory conditions were compared for each vessel $(r>.68)$. The overall picture, thus, is one of great similarities. Of the nearly 1,300 correlations calculated, only about $11 \%$ were not statistically significant [using the more liberal one-tailed test, where $r(10)=.49$, $p<.05$ ], and only 31 correlations of the total were negative (of which none was significant). In summary, men's and women's judgments of four ceramic vessels, either collectively or individually, on each of 12 affectivecognitive-sensory scales, were highly related regardless of mode of input (visual, tactile, or both combined).

The finding of near equivalence between the senses may have depended on the peculiar nature of the task or the stimuli used. These possibilities were examined in two additional studies. In Experiment 2, subjects imagined seeing or touching ceramic vases; in Experiment 3, subjects were presented with clay shards of discarded vessels. Experiment 3 also directly compared the two kinds of sensory input; the same subjects were used in all conditions.

\section{EXPERIMENT 2}

\section{Method}

Two sets of booklets were distributed to a general psychology undergraduate class, following a 10 -min introduction to the topic of imagery and a poll of the kinds of imagery students had. Each booklet contained the 12 scales used in Experiment 1 (arranged in one of four orders), 
along with one of two kinds of instructions. Subjects were instructed to imagine that they were either seeing or touching a hand-sculptured object "like a clay or ceramic vase" ( $N=13$ and $N=11$, respectively).

\section{Results}

The visual and tactile imagery ratings on 4 of the 12 scales differed. Visual images were reported as more complex than tactile images [mean $=6.18$ and 4.77 , respectively; $t(22)=1.83, p<.05$, one-tailed test]. (This scale was also differentially responded to in Experiment 1 where real vessels were used, although the effect depended on the particular stimulus used.) Visual images were also reported to be more detailed than tactile ones [mean = 2.54 and 4.82 , respectively; $t(22)=2.55, p<.05$, twotailed test], larger [mean $=3.15$ and 4.73 , respectively; $t(22)=2.04, p=.05$, two-tailed test], and warmer [mean $=4.92$ and 5.91 , respectively; $t(22)=1.72, p=.05$, one-tailed test]. The correlations between the scales across the two modes were high $(r=.63, p<.05$, two-tailed test).

Consequently, the general picture is again one of similarities rather than differences: 8 of the 12 scales showed no differences. Where differences existed, several were based on the more liberal one-tailed test.

\section{EXPERIMENT 3}

\section{Method}

Unglazed but fired ceramic scraps (from the waste bins of a pottery studio) were used in Experiment 3. Three white and generally similar (i.e., cylindrical) shapes of the same texture (i.e., slightly rough) were used. They ranged from about 10 to $20 \mathrm{~cm}$ in height, and about 2 to $9 \mathrm{~cm}$ in width. Each was mounted in a box which could be masked so as to allow only the subjects' hands to touch the object without seeing it.

Seventeen female and 12 male volunteers (for credit) from an introductory psychology class were individually tested. Each subject looked at, touched, and both looked at and touched each of the three scraps in a predetermined order. (Both hands were used in the touching tasks; the scraps could not be lifted.) A rating sheet containing the 12 scales, used previously in Experiments 1 and 2, was completed after each type of sensory presentation. Ten seconds were allowed for each presentation, followed by the completion of the scales (average time $30 \mathrm{sec}$ ). The subjects moved immediately to the next stimulus upon completion of their ratings. Subjects were encouraged to rely on their first impressions and to work quickly. The order in which the conditions were presented, the scraps used in each condition, and the arrangement of the rating scales were varied in a predetermined order for each subject. Each ceramic scrap was presented in each of the three sensory modes an equal number of times. In the analysis that follows, the scores for each mode of presentation were combined for the three scraps used.

\section{Results}

Only one scale, cold-hot, was influenced by the mode of presentation, and the effect varied with sex $[F(2,54)=$ $5.39, p<.01]$ : men saw the scraps as hotter than females did (mean $=3.67$ and 3.18, respectively), and women felt them as hotter than men did (mean $=3.53$ and 3.08 , respectively); the sexes did not differ on the combined mode (mean $=3.53$ and 3.42 , respectively). (This scale was not differentially responded to in either Experiment 1 or Experiment 2.)

The 12 scales, compared across the three modes of presentation, were significantly correlated in each case $(r>.86, p<.01)$. These results parallel the correlational and ANOVA analyses of Experiments 1 and 2, where the subjects received only one of the three modes of presentation.

\section{DISCUSSION}

Visual and tactile input in the three studies were judged to be more similar to one another than different. When ceramic vessels were rated (Experiment 1), differences between vision and touch existed in only two cases, and these depended on the particular stimuli used. When visual and tactile imagery for vessels were compared (Experiment 2), only 4 of the 12 scales differed. And when broken ceramic shards were compared (Experiment 3), only 1 scale differed (and it depended on the sex of the subjects). The homogeneity of the data was further illustrated by very high correlations between visual, tactile, and combined responses in each of the three studies. These results are congruent with a sensory equivalence model of information processing (J. J. Gibson, 1966).

There are obvious and major distinctions between vision and touch: each depends on different kinds of physical input and receptor transformations at either the eye or the skin. Nevertheless, the two senses have the same general functions in common: they extract, pick up, and organize information about the world. Although the sensory mechanisms and pathways of vision and touch are quite different from one another in several important ways, the information registered by each sense is, in its essentials, the same. A rough, crooked, and heavy object is seen and felt as rough, crooked, and heavy despite anatomical and other differences in the visual and tactile details. Input, irrespective of modality, contains common attributes, higher order similarities, and underlying invariants (J. J. Gibson, 1966). These parallels are sufficient to supersede the differences between the senses. The processing of visual and tactile input is interrelated, holistic, amodal, and nonspecific.

These experiments maximized the equivalence of seeing and touching by using, imagining, or suggesting aesthetic objects (Experiment 1, 2 , or 3, respectively). (Although scraps were used in Experiment 3, they were still fairly complex and unordinary. Hence, quasi-aesthetic qualities may have been suggested by their "free-form" shapes.) Aesthetic objects, as "good forms," are highly potent sources of visual and tactual information (Lederman \& Abbott, 1981). Objects look the way they feel and feel the way they look, if the objects make strong visual and tactile demands, as aesthetic objects are likely to do.

The kind of task employed-rating the objects' sensory, perceptual, and cognitive connotations-also favored a holistic (i.e., cross-modal) response. Subjects were implicitly encouraged to be open to their impressions and feelings and to interpret their experiences freely (i.e., to give a phenomenological reaction [Katz, as cited in Krueger, 1970; Wong, 1975]). Consequently, mediation among and between various processes, despite their initiation by different sensory modes, could easily take place.

\section{REFERENCES}

Garbin, C. P., \& Bernstein, I. H. (1984). Visual and haptic perception of three-dimensional solid forms. Perception \& Psychophysics, 36, 104-110.

GiBSON, E. J. (1969). Principles of perceptual learning and development. New York: Appleton-Century-Crofts.

Gibson, J. J. (1962). Observations on active touch. Psychological Review, 69, 477-491.

Gibson, J. J. (1963). The useful dimension of sensitivity. American Psychologist, 18, 1-15.

GIBSON, J. J. (1966). The senses considered as perceptual systems. New York: Houghton Mifflin.

Kennedy, J. M. (1978). Haptics. In E. C. Carterette \& M. P. Friedman (Eds.), Handbook of perception (Vol. 8, pp. 289-318). New York: Academic Press.

Krauthamer, G. (1968). Form perception across sensory modalities. Neuropsychologia, 6, 105-113. 
Krueger, L. E. (1970). David Katz's Der Aufbau der Tastwelt (The world of touch): A synopsis. Perception \& Psychophysics, 7, 337-341.

KRUEGER, L. E. (1982). Tactual perception in historical perspective: David Katz's world of touch. In W. Schiff \& E. Foulke (Eds.), Tactual perception: A sourcebook (pp. 1-54). Cambridge: Cambridge University Press.

LeDERMAN, J. J. (1982). The perception of texture by touch. In W. Schiff \& E. Foulke (Eds.), Tactual perception: A sourcebook (pp. 130-167). Cambridge: Cambridge University Press.

Lederman, J. J., \& ABbOTt, S. G. (1981). Texture perception: Studies of intersensory organization using a discrepancy paradigm and visual versus tactual psychophysics. Journal of Experimental Psychology: Human Perception \& Performance, 7, 902-915.

MARKs, L. E. (1978). The unity of the senses: Interrelations among the modalities. New York: Academic Press.

OWEN, D. H., \& BRown, D. R. (1970). Visual and tactual form complexity: A psychophysical approach to perceptual equivalence. Perception \& Psychophysics, 7, 225-228.

Revesz, G. (1950). Psychology and art of the blind. (H. A. Wolff, Trans.). London: Longmans, Green.

Richardson, J. T. E., Ainsley, H. M., Copsey, S., \& Watkins, S. A.
(1980). The role of tactual information in the recall of concrete objects. Bulletin of the Psychonomic Society, 16, 57-58.

Rock, I., \& Victor, J. (1964). Vision and touch: An experimentally created conflict between the two senses. Science, 143, 594-599.

Rowland, W. (1974). An experiment in art appreciation by touch. New Beacon, 58, 115-117.

Taylor, M. M., Lederman, S. J., \& Gibson, R. H. (1973). Tactual perception of texture. In E. C. Carterette \& M. P. Friedman (Eds.), Handbook of perception (Vol. 8, pp. 251-272). New York: Academic Press.

von Hornbostel, E. M. (1955). The unity of the senses. In W. D. Ellis (Ed.), A source book of Gestalt psychology (pp. 210-216). London: Routledge \& Kegan Paul.

WoNG, E. (1975). Visual and tactile perception reconsidered from an empirical phenomenological perspective. Journal of Phenomenological Psychology, 6, 75-87.

YoshidA, M. (1968). Dimensions of tactual impressions (1). Japanese Psychological Research, 123-137.

(Manuscript received for publication November 18, 1985.) 